Bangladesh J. Bot. 48(1): 105-111, 2019 (March)

\title{
MORPHOMETRIC AND GENETIC CHARACTERIZATION OF MEDICINALLY IMPORTANT ACCESSIONS OF PHYSALIS IXOCARPA BROT.
}

\author{
WaJid KhaN*, Jehan Bakht ${ }^{1}$, Bilal Muhammad Khan ${ }^{2}$, IJaz NaEem ${ }^{3}$, \\ Muhammad Nazir Uddin and Bilal A Padder ${ }^{2}$ \\ Center for Biotechnology and Microbiology, University of Swat, Pakistan \\ Keywords: Genetic similarity matrix, RAPD, Accessions, Physalis ixocarpa
}

\begin{abstract}
To support the crop improvement of Physalis ixopcarpa Brot., 16 accessions provided by National Plant Germ Plasm System USDA (USA) and one recently reported accession from Pakistan were characterized for morphometric and genetic diversity. These accessions were evaluated for morphometric and physiological traits. Among these traits, plant height, relative water content, total chlorophyll content, per cent germination and leaf area were found as best for the differentiation among these accessions. These accessions were also screened for genetic differentiation using RAPDs primers. The genetic similarity among accessions was in the range of 0.03 to 0.33 . The RAPD data supported the ecological distribution of accessions. It is inferred from molecular typing that accessions PI512005 and PI360740 were the most diverse accessions among the accessions of $P$. ixocarpa. In this study the genetic data were deviated from morphometric data which might be due to the qualitative and quantitative characteristics of accessions influenced by environmental factors.
\end{abstract}

\section{Introduction}

Physalis ixocarpa commonly called Tomatillo, belongs to the genus Physalis and family Solanaceae. Its fruits are used to prepare traditional dishes such as Mole Amirolo de Oxaca, the local dish of Mexico, its extract has high anticancer, anti-angiogenic, anti-inflammatory and other medicinal properties (Hsua et al. 2011, Zhang et al. 2016, Khan et al. 2016). Due to existence of 70 different species of Physalis in Mexico makes it becomes the center of origin (Vargas-Ponce $e t$ al. 2011). To have a long-term success in the $P$. ixocarpa improvement it is essential to have accurate knowledge about the diversity within the germplasm collection. Further, natural diversity represents an important genetic diversity source and can be if exploited in the breeding programs which will result in speedy development of cultivars. Among the various Physalis species, diversity studies using different molecular markers have been carried out for a few species such as P. peruviana (Garzon-Martinez and Jaime 2015), P. philadelphica (Zamora-Tavares et al. 2015). There is dearth of information about the morphology and genetic diversity of P. ixocarpa. Information on its diversity is necessary to improve its quality and other agronomic traits. During the past few years emphasis on the morphology of $P$. ixocarpa has revealed about its wider adoptability to different environmental conditions with varying agronomic traits (Coşkun 2017, Ramírez-Godina et al. 2013). Phenotypic traits studied are highly influenced by the environment. To have unbiased environment influence on the traits, molecular markers are best choice for deducing the variability among different accessions of P.ixocarpa.

\footnotetext{
*Author for correspondence: <sherafghan.shah@gmail.com>. ${ }^{1}$ Institute of Biotechnology and Genetic Engineering, The University of Agriculture Peshawar, KPK Pakistan. ${ }^{2}$ Guangdong Provincial Key Laboratory of Marine Biotechnology, STU-UNIVPM Joint Algal Research Center, Department of Biology, College of Science, Shantou University, Shantou, Guangdong 515063, PR China. ${ }^{3}$ Department of Microbiology, University of Swabi.
} 
Molecular markers are un-influenced by the environmental conditions besides having other advantages over the morphological markers. Owing to the dearth of information about $P$. ixocarpa diversity and its economical and medicinal properties, the present study was carried out with the objective to evaluate the genetic and morphometric variability among the accessions for their efficient future breeding program in Pakistan and to ascertain the relationship of $P$. ixocarpa collected from Pakistan with the USDA accessions.

\section{Materials and Methods}

In the present study 16 accessions of Physalis ixocarpa provided by the National Plant Germplasm System USDA (USA) and one indigenous accession of $P$. ixocarpa collected from district Shangla KPK, Pakistan were evaluated for morphometric and genetic differentiation (Table 1). Experiments for evaluation process were carried out in greenhouse located at Institute of Biotechnology and Genetic Engineering, The University of Agriculture Peshawar. Seeds of accessions were sown in plastic pots with mixture of sieved soil, organic matter, and sand (3:1:1). The experiment was performed in completely randomized design (CRD) with ten (10) replicates.

Table 1. Different accessions of Physalis ixocarpa (Tomatillo) used in the present study.

\begin{tabular}{llll}
\hline Taxon & Accession lot & ID & Origin \\
\hline Physalis ixocarpa & PI360740 & G222124 & Ecuador \\
Physalis ixocarpa & PI309812 & Tomate & Mexico \\
Physalis ixocarpa & PI512009 & Pop or Poposokol & Mexico \\
Physalis ixocarpa & PI662844 & G30152 & Mexico \\
Physalis ixocarpa & PI512010 & Tomate & Mexico \\
Physalis ixocarpa & PI512008 & Tomate & Mexico \\
Physalis ixocarpa & PI512909 & G 13134 & Argentina \\
Physalis ixocarpa & PI512011 & Tomatillo & Mexico \\
Physalis ixocarpa & PI662843 & G 3015 & Mexico \\
Physalis ixocarpa & PI512005 & Tomatillo & Mexico \\
Physalis ixocarpa & PI512006 & Tomatillo & Mexico \\
Physalis ixocarpa & PI270459 & G 349 & Mexico \\
Physalis ixocarpa & PI662845 & Rendidora & United States \\
Physalis ixocarpa & PI662846 & G30319 & United States \\
Physalis ixocarpa & PI662847 & Pervuvian & United States \\
Physalis ixocarpa & PI291560 & Tomatillo & India \\
Physalis ixocarpa & & & Pakistan \\
\hline
\end{tabular}

Thirteen morphological traits divided into 9 quantitative (leaf Area, plant height, root length, petiole length, fresh weight, dry weight, total chlorophyll, relative water content and per cent germination) and 4 qualitative (calyx ribbing, calyx color, leaf blade dentation, plant body position) were studied under greenhouse conditions. Physiological variables such as total chlorophyll content (Arnon 1949), relative water content (Bajji et al. 2001) and per cent germination (Giri and Schillinger 2003) were also measured. Qualitative variables such as calyx color, leaf morphology and body position were also observed in this study.

DNA was isolated from fresh leaves of each accession following the procedure of Weining and Langridge (1991) with little modification. Optimized protocol of PCR (Devos and Gale 1992) 
was applied to amplify the genomic DNA using Randomly Amplified Polymorphic DNA (RAPD) primers. The detail of standard protocol was previously reported by Shuja et al. (2011).

Statistical analysis of morphometric data were done on MSTATC computer software (Russel and Eisensmith 1983). The phenogram and dendogram were constructed using NTSYS software.

\section{Results and Discussion}

Information on morphometric, agronomic and genetic diversity of the accession of Physalis ixocarpa is limited. For breeding purpose, the characterization of these accessions is required. $P$. ixocarpa being an important crop having culinary and medicinal properties has not been studied worldwide and no information is available about the morphometric and genetic study of accessions of Physalis ixocarpa that are reported from different regions of the world. In the light of this fact the morphometric and molecular analysis of the accessions belonging to different parts of the world were compared. In the present study, the accessions of P. ixocarpa grown under greenhouse condition exhibited considerable variation at morphometric and molecular level. All the quantitative traits analyzed in this study showed significant differences among accessions (Table 2).

Morphometric analysis indicated the most important characters in the differentiation of accessions were plant height, total chlorophyll content, and root length and leaf area. Leaf is a very important characteristic for germplasm characterization (Mudibu et al. 2011). Accession No. PI662843 attained maximum leaf area while minimum leaf area was noted for accession P1512008. The highest root length was observed in PI512009 followed by PI. On the other hand, the smallest root length was measured in accession PI512008 followed by PI512011. Maximum plant height showed by accession PI $(55 \mathrm{~cm})$ as compared to other accessions. The population PI512010 had highest total chlorophyll content with respect to other populations. No correlations were noted for quantitative traits under study. Similar findings were also reported by Malik et al. (2005) who studied correlation among various quantitative traits in maize. Less variation was seen in qualitative traits of the accession. All accessions have calyx ribbing except PI270459 and PI662846. Most of the accessions including the accession collected from Pakistan have green color calyx, however blue and dark green color was seen only in two accessions (PI662847 and PI291560). Medium leaf dentation was found in 59\% accessions. Medium type of leaf dentation is common (59\%), but some have poor leaf dentation. Here the qualitative traits are not correlated to quantitative traits but signify the important taxonomic features for germplasm evaluation. The present results are in agreement with the findings of Mudibu et al. (2011)

The phenogram constructed from quantitative and qualitative traits revealed the wide range of morphometric similarity coefficient between accessions. The population PI512010, PI662843; PI52008 and PI512909 showed highest similarity coefficient while the lowest coefficient was seen among PI360740, PI662845; PI360740 and PI. The accession from Pakistan (PI) was appeared in cluster III of phenogram with six more accession. PI accession showed more similarity to PI512011.

Genetic diversity in P. ixocarpa has been based on the variation in morphometric, agronomic traits and pedigree information. This assessment is essential for breeding programs (Rout and Mohapatra 2008, Tamkoc and Arslan 2011). The phenotypes are highly subjective by environmental factors ( $\mathrm{Li}$ and Nelson 2001) and therefore molecular markers have been preferred to evaluate genetic diversity of accessions (Hand et al. 2012a, Arslan and Tamkoc 2011). Out of 32 RAPD primers, eight (8) primers (GL G-13, GL F-12, GL E-14, GL C-18, GL H-08, GL A-04, GL E-16 and GL E-11) produced discrete, reproducible and prominent bands and were used for the analysis of genetic diversity among these accessions. The maximum genetic similarity was 


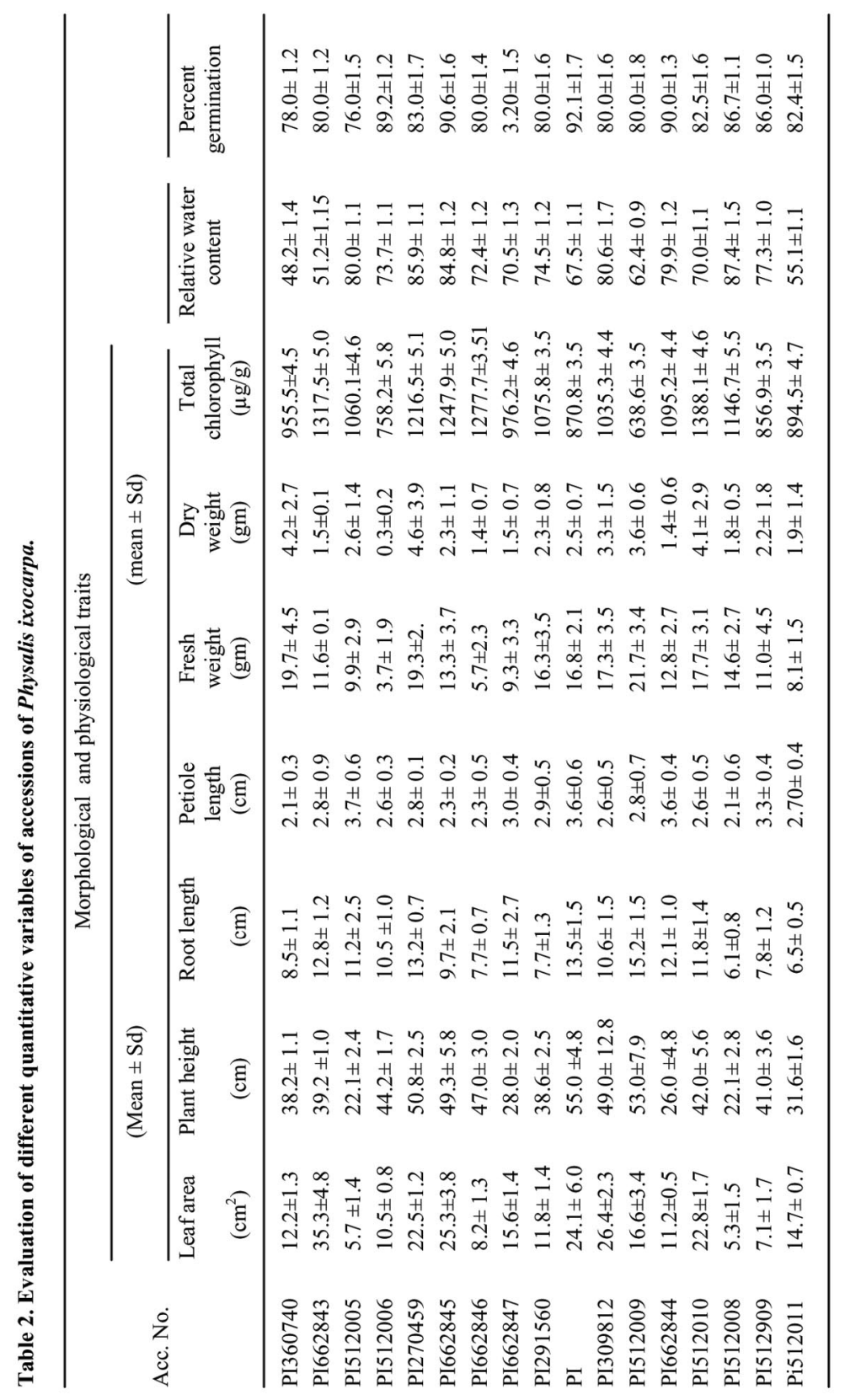


observed between two combinations (PI512909 and PI66843, PI662845 and PI662846) and minimum genetic similarity with high genetic diversity was shown by PI360740 and PI512005. The accession PI of Pakistan showed more similarity to PI291560 and PI662847 as compared to other populations and appeared in cluster II of the dendogram.

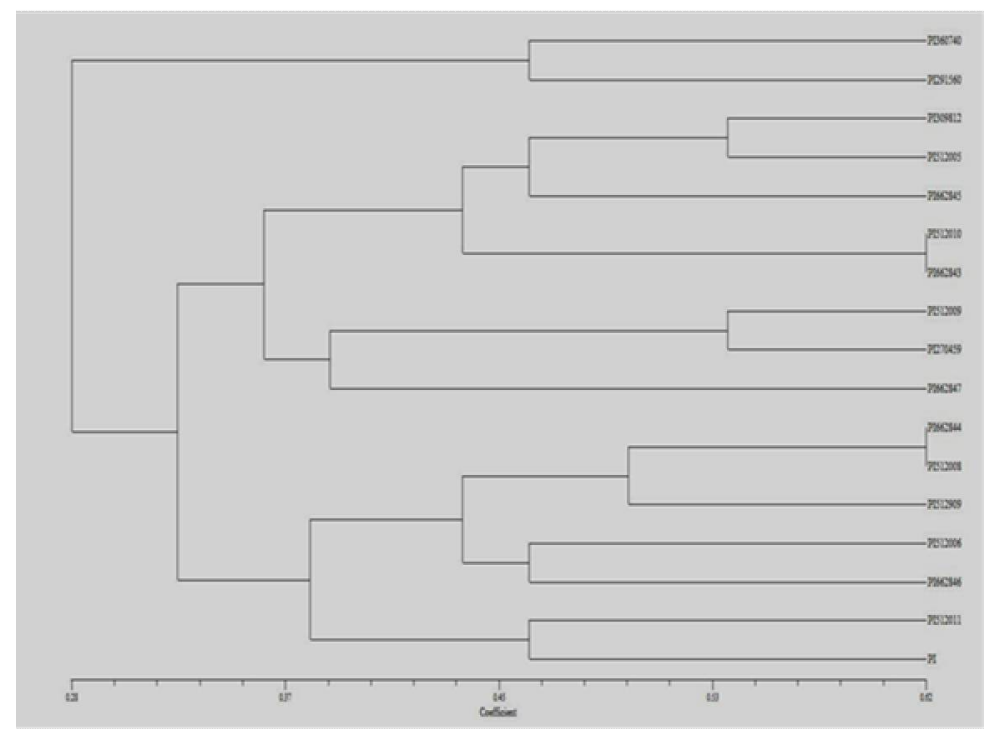

Fig. 1. Phenogram showing morphogenetic similarity among the accessions of Physalis ixocarpa

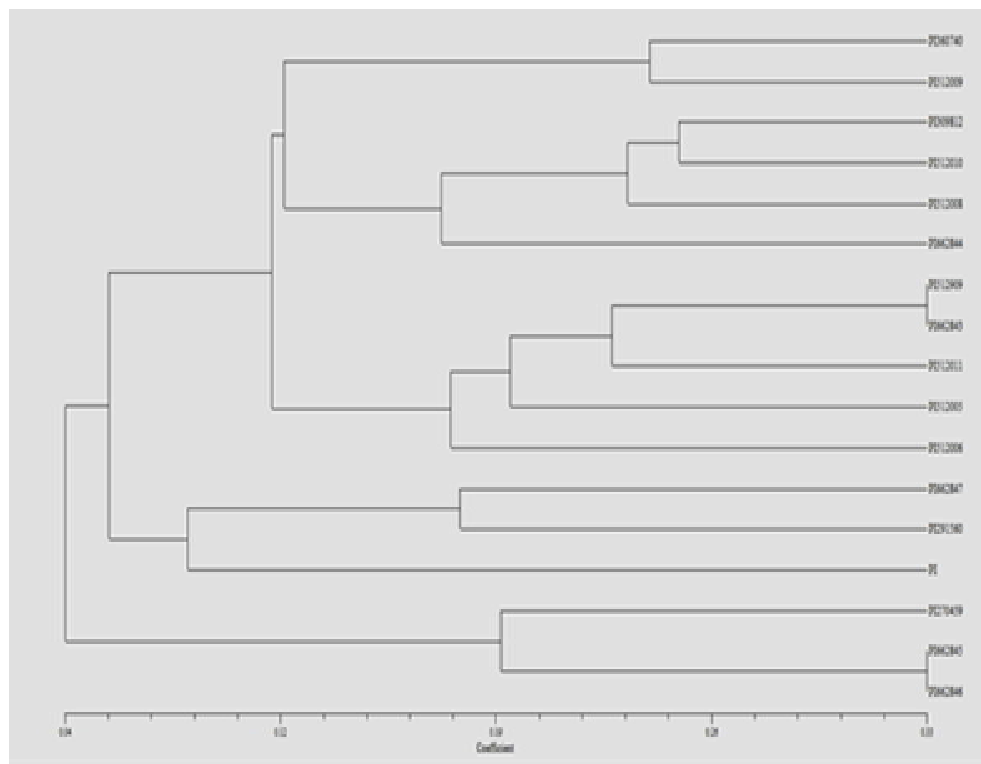

Fig. 2. Dendogram of 17 accessions of Physalis ixocarpa using RAPDs primers. 
The dendogram and phenogram presented the three groups of accessions, however, different accession was appeared in each group. Structure of the trees presented some of the accessions grouped in same cluster in both trees while in other cases the result varied from each other. The populations PI512909 and PI662843, PI360740 and PI512009 appeared as the same accessions in dendogram but morphologically they were quite different from each other. Similarly, some accessions appeared on the same bars of phenogram suggesting the same accessions but were genetically dissimilar. The deviation of morphometric data from genetic data might be due to the quantitative and qualitative traits of accessions which are subjective by environmental factors (Costal et al. 2006, Tiwari et al. 2011). The appearance of blue color calyx in population PI662847 cannot be confirmed during molecular study. The deviation in calyx color might be due to intraspecific variation found or dominant feature of RAPD markers which cannot discriminate homo and heterozygotes (Costal et al. 2006). The results of the study stated no correlation between the morphometric and genetic data. The lack of this correlation might be due to the quantitative and qualitative characteristics of accessions influenced by environmental factors.

The information obtained from dendogram supported the distribution region of the accessions (Krebs et al. 2010). Structure of the dendogram revealed that the Mexican and American accessions of P.ixocarpa were clustered in separate groups. The data further stated that new accession from Pakistan was grouped with accession collected from India which supported and strengthened the correlation between genetic and geographic regions of the accessions.

From the above study it may be concluded that the characterization of the accession based on set of evaluated variables facilitated the identification and documentation of accessions of given species. The populations PI360740 and PI512005 were identified as genetically diverse accession and can be used for future breeding program. Moreover, the current molecular data also supported the ecological distribution and relation among the isolated geographic population.

\section{Acknowledgements}

The authors acknowledge the National plant germ plasm system USDA (USA) for providing the seeds of accessions of P.ixocarpa.

\section{References}

Arnon DL 1949. Copper enzymes in isolated chloroplasts. Plant Physiol. 24: 1-15.

Arslan E and Tamkoc A 2011. The application of ISSR-PCR to determine the genetic relationship and genetic diversity between narrow leaved bluegrass (Poa angustifolia) and rough bluegrass (Poa trivialis) accessions. Turkish J. Biol. 35: 415-423.

Bajji M, Lutts and Kinet S 2001. Water deficit effects on solute contribution to osmotic adjustment as a function of leaf ageing in three durum wheat (Triticum durum Desf) cultivars performing differently in arid conditions. Plant Sci. 160: 669-681.

Coşkun Y 2017. Determination of some traits of different tomatillo genotypes (Physalis Ixocarpa Brot.) under the çanakkale conditions. PIJR. 5: 456-458.

Costa1 F R, Pereira1 TNS, Vitórial AP, Campos K P, Rodrigues R, Silva D H and Pereira1 MG 2006. Genetic diversity among Capsicum accessions using RAPD markers. Crop Breed Appl Biotechnol. 6: 18-23.

Devos, K. and Gale M.D 1992. The use of randomly amplified marker in wheat. Theor. Appl. Genet. 101: $107-118$

Garzón-Martínez GA and Jaime A 2015. Osorio-Guarín, Paola Delgadillo-Durán, Franklin Mayorga, Felix E. Enciso-Rodríguez, David Landsman, Leonardo Mariño-Ramírez, and Luz Stella Barrero. "Genetic diversity and population structure in Physalis peruviana and related taxa based on InDels and SNPs derived from COSII and IRG markers." Plant gene 4: 29-37. 
Giri GS and Schillinger WF 2003. Seed priming winter wheat for germination emergence and yield. Crop Sci. 43: 2135-2141.

Hand ML, Cogan NOI and Forster JW 2012a. Molecular characterization and interpretation of genetic diversity within globally distributed germplasm collections of tall fescue (Festuca arundinacea Schreb.) and meadow fescue (F. pratensis Huds.). Theor. Appl. Genet. 124: 1127-1137.

Hsua Y, Wub C, Changc H, Kumara K, Linb M, Cheni C, Hoi HC, Huangi C, Huangd C, Leee H, Hsiehf W, Chungg J, Wangh H and Yangi H 2011. Inhibitory effects of Physalis angulata on tumor metastasis and angiogenesis. J. Ethnopharmacol. 135: 762-771.

Khan W, Bakht J and Shafi M 2016. Antimicrobial potentials of different solvent extracted samples from Physalis ixocarpa. Pak J Pharm Sci. 29:467-75.

Krebs C, Mahy G, Matthies D, Schaffner U, Tie bre MS and Bizou JP 2010. Taxa distribution and RAPD markers indicate different origin and regional differentiation of hybrids in the invasive Fallopia complex in central-western Europe. Plant Biol. 12: 215-223.

Li Z and Nelson R 2001. Genetic diversity among soybean accessions from three countries measured by RAPDs. Crop Sci. 41: 1337-1347.

Malik HN, Malik SI, Hussain M, Chughtai SUR and Javed HI 2005. Genetic correlation among various quantitative characters in maize (Zea mays L.) hybrids. J. Agric. Soc. Sci. 3: 262-265.

Mudibu J, Nkongolo KKC and Kalonji-Mbuyi A 2011. Morpho-variability and agronomic characteristics of soybean accessions from the Democratic Republic of Congo (DR-Congo) gene pool. J. Plant Breed. Crop Sci. 3: 260-268.

Ramírez-Godina, F, Robledo-Torres V, Pournabav RF, Benavides-Mendoza A, Hernández-Piñero JL, ReyesValdes MH and Alvarado-Vázquez MA 2013. Yield and fruit quality evaluation in husk tomato autotetraploids (Physalis ixocarpa) and diploids. Aust J Crop Sci. 7: 933.

Rout GR and Mohapatra A 2008. Use of molecular markers in ornamental plants: A critical reappraisal. Eur. J. Hortic. Sci. 71: 53-68

Russell DF and Eisensmith SP 1983. MSTAT-C. Crop Soil Sci. Dept., Michigan State Univ., USA.

Shuja MN, Khan W, Iqbal A, Ali I, Munir I, Ahmad D, Inamullah, Shah S, Ahmad G, Khan MA and Swati ZA 2011. Maize breeding for marginal lands: Physiological and molecular approach to decipher response and selection of maize recombinant inbred lines (RILs) under water deficit at early growth stage. Afr J Biotechnol. 10: 3521-3527.

Tamkoc A and Arslan E 2011. Inter and Intra-specific variation in SDS-PAGE of seed proteins in three Poa L. (Poaceae) Species. Pak J Bot. 43: 1105-1110.

Tiwari P, Kumar B, Kaur M, Kaur G and Kaur H 2011. Phytochemical screening and extraction: A Review. Inter Pharma. Sci. 1: 98-106.

Vargas-Ponce O, Perez LF, Zamora P and Rodr1'guez A 2011. Assessing genetic diversity in mexican husk tomato species. Plant Mol. Biol. Rep. 29: 733-738.

Weining S. and Langridge P 1991. Identification and mapping of polymorphism in cereals based on polymerase chain reaction. Theor. Appl. Genet. 82: 209-216.

Zamora-Tavares P, Vargas-Ponce O, Sánchez-Martínez J and Cabrera-Toledo D. 2015. Diversity and genetic structure of the husk tomato (Physalis philadelphica Lam.) in Western Mexico. Genet Resour Crop Ev. 62: 141-153.

Zhang CR, Khan W, Bakht J and Nair MG 2016. New antiinflammatory sucrose esters in the natural sticky coating of tomatillo (Physalis philadelphica), an important culinary fruit. Food Chem. 196: 726-732.

(Manuscript received on 28 May, 2018; revised on 10 July, 2018) 